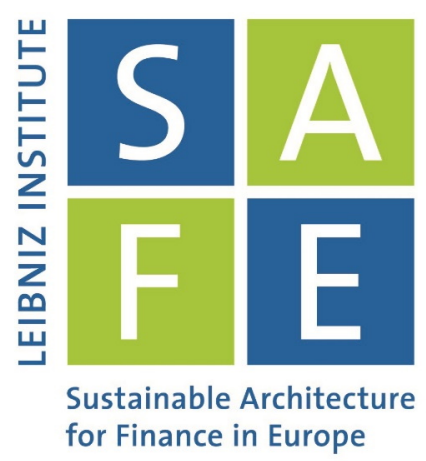

Kevin Bauer

\title{
How did we do? The Impact of Relative Performance Feedback on Intergroup Hostilities
}

SAFE Working Paper No. 281

\section{Leibniz Institute for Financial Research SAFE}

Sustainable Architecture for Finance in Europe 


\title{
How did we do? The impact of relative performance feedback on intergroup hostilities
}

\author{
Kevin Bauer \\ Leibniz Institute for Financial Research SAFE, Theodor-W.-Adorno-Platz 3, D-60323 Frankfurt am Main, Germany \\ Bauer@safe.uni-frankfurt.de \\ Using a novel experimental design, I test how the exposure to information about a group's relative perfor- \\ mance causally affects the members' level of identification and thereby their propensity to harm affiliates \\ of comparison groups. I find that both, being informed about a high and poor relative performance of the \\ ingroup similarly fosters identification. Stronger ingroup identification creates increased hostility against the \\ group of comparison. In cases where participants learn about poor relative performance, there appears to be \\ a direct level effect additionally elevating hostile discrimination. My findings shed light on a specific channel \\ through which social media may contribute to intergroup fragmentation and polarization.
}

Key words: social identity, relative performance feedback, discrimination, outgroup derogation

\section{Introduction}

Over the past decade, there has been a steady growth in the number of active users on social media platforms (see for example Pew Research Center 2018). Today, social media has become an integral part of many people's everyday life (Bennett 2015, Robb 2015). Facebook (together with its sister platforms) alone registers 2.5 billion monthly active users globally (Facebook 2020) who on average spend 50 minutes per day online (Facebook 2016). This appears to be particularly the case for millennials (Wallace 2015, Pew Research Center 2019). One consequence of this development is that people's exposure to information delivered via news feeds, posts, and messages has considerably increased. Frequently, the information includes cues about the achievements and failures of groups individuals associate themselves with (ingroups). Examples range from politicians posting election results, companies informing followers that they have outperformed competitors in some ranking, to universities and students proliferating their football team's latest victory on the platform. From the perspective of social psychology and economics, the exposure to cues of the ingroup's performance relative to other groups a person does not associate herself with (outgroups), may incite important cognitive and behavioral responses (Tajfel and Turner 1979, Brown 2000, Hornsey 2008, Chen and Li 2009). Specifically, learning that the ingroup has performed poorly or well relative to an 
outgroup, evinces social comparison processes (Festinger 1954) which affect ingroup identification and thereby possibly intergroup discrimination.

Previous empirical research has documented that individuals tend to flaunt their association with groups in front of themselves and others, in case they learn about high relative performance. In contrast, people try to conceal their affiliations with groups when they learn about poor relative performance (Cialdini et al. 1976, Wann et al. 1995, End et al. 2002, Boen et al. 2002a, 2002b). Apart from these insights, and despite its importance for intergroup relations, there is a lack of causal evidence on the relationship between exposure to information about an ingroup's relative performance, the strength of identification and intergroup discrimination. The paper at hand intends to address this gap. In particular, I draw on social identity theory as an explanatory framework to study whether learning about the ingroups' relative performance affects group identities and thereby hostile discrimination against outgroups to which the ingroup is compared to.

Identifying causal links poses two major challenges. First, the development and enhancement of group identities are generally affected by a vast number of unobserved and individually-weighted factors as it is an inherently psychological process. Second, whether groups perform well or poorly relative to other groups depends on a variety of highly endogenous factors that are likely to influence identification and intergroup hostilities. To circumvent resulting self-selection and omitted variables concerns, I employ a novel lab experiment providing me with necessary control over potential confounds.

In the experiment, individuals are randomly assigned to different minimal groups that compete with each other for five rounds in a modified version of the "Rock-paper-scissors" game. A majority decision determines the symbol that is played by the group as a whole in a particular round. Feedback is reduced to a minimum, such that participants cannot infer actual choices of other subjects or groups. Given this structure of the game, the relative performance of the group is effectively randomly assigned. At the same time, the group's performance is not imposed by the experimenter but the result of the group's aggregated choices. To resemble the mere exposure to information without any immediate consequences on personal material well-being, neither winning nor losing have consequences for subsequent experimental tasks or ultimate payoffs. After notifying subjects about whether their group has won or lost, individuals' group identification levels are measured. In the subsequent part of the experiment, subjects are asked to make a series of allocation choices, which exclude self-interest by design. These choices are used to reveal how conveyed feedback incites hostile discrimination specifically targeted against the opposing group. I compare observations from the treatment to results from a control condition, where groups also competed 
but participants did not receive information about competitive outcomes, to isolate effects from exposure to information about the group's performance and the act of competing itself.

The paper at hand makes three contributions. First, I document a causal link between the exposure to information about the ingroup's relative performance and ingroup identification. I find both learning about high and poor performances of the group to amplify the extent to which people identify with their group. Second, being exposed to information about the ingroup's relative performance increases discrimination specifically targeted against the opposing group. Effects are more pronounced if individuals learn about a poor relative performance. Third, I find this increase in discrimination to be, at least partially, causally driven by fostered levels of ingroup identification. Exposure to information about a poor relative performance additionally creates a level effect.

My findings shed light on a specific channel through which social media may affect intergroup fragmentation and polarization. Presented results suggest that the frequent exposure and vast proliferation of information about groups' relative successes and failures may enhance people's ingroup identification and thereby incite hostile discrimination. For instance, this mechanism may provide a partial explanation why social media posts of political leaders propagating the political achievements of their parties frequently lead to hostile controversies in the commentary sections. ${ }^{1}$

In that sense, my results relate to ongoing debates about the role that social media plays in the process of intergroup polarization, especially political polarization (see Tucker et al. 2018 for a comprehensive literature overview). There is a growing concern that social media can create "echo chambers" and "identity bubbles" that reduce encounters with diverse viewpoints and thus foster political polarization and growing cross-party hostility along partisan lines (Sunstein 2007, 2018, Pariser 2011, Gentzkow 2016, Tucker et al. 2017, Settle 2018, Kaakinen et al. 2020). Social media enables individuals to easily engage in selective information consumption where they only seek out information that does not challenge their views to reaffirm and reinforce their political and ideological attitudes through like-minded social media use (Slater 2007, Bennett and Iyengar 2008). In line with these arguments, Alcott et al. (2020), using a randomized field experiment, find that deactivating Facebook for the four weeks before the 2018 US midterm election has, among other things, led to a reduction in political polarization. The causal effects I document in the paper at hand may constitute one of the mechanisms that underlie this observation by Alcott et al. (2020) and (Gentzkow 2016).

Additionally, my findings supplement previous work on social identity. Specifically, reported results support existing theories which conceptualize identification as a choice governed by specific

\footnotetext{
${ }^{1}$ For two recent examples see https://twitter.com/JoeBiden/status/1268695278611095557?cxt= HHwWioCjncrop5sjAAAA, and https://www.instagram.com/p/CBCHZjMhLOC/?utm_source=ig_web_copy_link (both accessed on June 5, 2020)
} 
preferences (Akerlof and Kranton 2000, Shayo 2009, Bernard et al. 2016) and past research advocating that differences in the strength of identification constitute as a natural source of variation in behavior (Kranton et al. 2016, Müller 2019, Hett et al. 2019).

Finally, from a conceptual point of view, I also contribute to the limited literature that provides empirical evidence on how relative performance feedback as such can shape economically relevant behaviors (see for example Kuhnen and Tymula 2012, Kosfeld and Neckermann 2011, Vidal and Nossol 2011), by showing that feedback on group performances as such may constitute a unitforming factor elevating ingroup identification and shaping discriminatory outcomes.

The remainder of the paper is organized as follows. In section 2, I summarize related literature and use tenets of social identity theory to conceptualize the impact of exposing people to feedback about their ingroup's relative performance on identification and thereby discrimination. My experimental design is explained in section 3. Results are shown in section 4. Finally, section 5 discusses results and concludes.

\section{Related literature and research hypotheses}

Social identity theory posits that an important part of who people are is determined by groups they identify themselves with. This part of people's self is generally referred to as their social identity (Tajfel 1974, Tajfel and Turner 1986). Groups people are identified with have been shown to form an important source for differential treatment of in- and outgroup members. For instance, social identities shape people's other-regarding concerns (Charness et al. 2007, Chen and Li 2009, Klor and Shayo 2010), their propensity to cooperate with others (Eckel and Grossman 2005, Goette et al. 2006) and their adherence to ingroup norms (Bernhard et al. 2006, McLeish and Oxoby 2011, Goette et al. 2012). The extent to which behavior is shaped depends on the level of identification with a group. The more people identify with a group, the more they tend to discriminate between in- and outgroup affiliates (Tajfel and Turner 1986, Akerlof and Kranton 2000, Chen and Li 2009).

In economics, identification with groups is conceptualized as a, more or less conscious, decision, motivated by utility-maximizing deliberations (Shayo 2009, Benjamin et al. 2010, Bernard et al. 2016, Hett et al. 2019). Following insights from social psychology (Tajfel and Turner 1979, Wagner and Zick 1990, Turner et al. 1987, van Dick 2001, 2004, Hornsey 2008, Leach et al. 2008), the amount of utility individuals derive from identifying with a specific group is assumed to depend on social comparisons between (i) the ingroup and outgroups, and (ii) people's personal characteristics and those of other ingroup members.

The first social comparison addresses the emotional value individuals attach to a group and is often referred to as the social status dimension. In general, people want to think of groups they identify with as being superior to groups of comparison in relevant social dimensions, i.e., to possess 
a high social status (Tajfel 1978, Tajfel and Turner 1979, Tajfel and Turner 1986, Ellemers and Baretto 2001). The more favorable these intergroup comparisons are, the more utility an individual gains if the group is a part of her social identity (Shayo 2009, Bernard et al. 2016).

The second social comparison is the cognitive component of social identity (van Dick 2004), emphasizing people' preference to associate with others who are perceived to be similar to themselves, a phenomenon sometimes referred to as homophily (McPherson et al. 2001, Currarini and Mengel 2012). Individuals gain more identity utility if their personal characteristics match the defining characteristics of the group, i.e., if they have a small social distance to the group (Shayo 2009, Bernard et al. 2016, Hett et al. 2019). Conceptualizing people's identification choices as weighing social status and social distance implies that the exposure to information about groups' relative performance influences the strength of identification with the group and thereby ultimately intergroup behavior.

In the following, I will formalize these notions and derive hypotheses about how the exposure to information about the ingroup's relative performance affects identification and intergroup discrimination. I develop a simple theoretical framework based on models proposed by Shayo (2009) and Chen and Li (2009), who extend Charness and Rabin's (2002) social preferences model.

Let there be a group $j$ with which an individual $i$ perceives to be affiliated. Following Shayo (2009), I assume the utility individual $i$ gains from identifying with group $j$ to have the following structure:

$$
U_{i, j}=S_{j} I_{i, j}-D_{i, j} c\left(I_{i, j}\right) .
$$

$\left.\left.I_{i, j} \in\right) 0,1\right)$ reflects the strength of identification of individual $i$ with group $j$. Identifying with a group is assumed to entail certain costs, which are described by some convex function $c($.$) . In$ analogy to Bénabou and Tirole (2011), these costs can be interpreted as an identity investment to internalize the group into the self-concept, e.g. restricting oneself to adhere to the group's norms. Identification costs increase with the perceived social distance to the group $D_{i, j}$ at a given point in time. Social distance is being modeled as Euclidean distance and defined as

$$
D_{i, j}=\left(\sum_{h=1}^{H} w_{h}\left(q_{i}^{h}-q_{j}^{h}\right)^{2}\right)^{\frac{1}{2}} .
$$

$q_{i}^{h}$ is person $i$ 's h-th characteristic and $q_{j}^{h}$ represents the corresponding trait of group $j$. For sake of convenience, $q_{j}^{h}$ is assumed to be the mean across members of group $j . w_{h} \in(0,1)$ represents the salience of attribute $h$ in a particular social context.

Group $j$ 's relative social status is given by

$$
S_{j}=\sigma_{j}\left(\tilde{\pi}_{j}-\tilde{\pi}_{R(j)}\right)
$$


$\tilde{\pi}_{j}$ depicts group $j$ 's measured performance in some dimension, e.g. generated revenues or sustainability efforts. $\tilde{\pi}_{R(j)}$ reflects the same performance measure for group $j$ 's reference group $R(j) . \sigma_{j}$ is a positive constant, accounting for the salience of the relative group performance.

Following this framework, being exposed to information about how the ingroup has performed relative to an outgroup affects $S_{j}$ and $D_{i, j}$. Let us first consider the impact on the social status dimension. In general, high relative performance is associated with success and superiority and has been found to yield some non-monetary benefits on a personal level (Sheremeta 2010, Mago et al. 2016). It should thus allow for favorable social comparisons to relevant outgroups. In particular, being informed about the ingroup's high relative performance increases the spread $\left(\tilde{\pi}_{j}-\tilde{\pi}_{R(j)}\right)$ and thus $S_{j} .{ }^{2}$ Ultimately identification with the group becomes more attractive and $I_{i, j}$ should increase. Receiving information about poor relative performance, in contrast, comes at some intrinsic depression (Delgado et al. 2008, Herbst 2016). Implying failure and subordination, it does not allow for a favorable comparison to other groups so that $\left(\tilde{\pi}_{j}-\tilde{\pi}_{R(j)}\right)$ and thus $S_{j}$ should decline. This effect renders identification less attractive, leading to a decrease in $I_{i, j}$. Next, consider the impact on the social distance component $D_{i, j}$. Informing members about whether their group has performed well or poorly, introduces another social dimension along which individuals can compare themselves to others. The common collective experience could, therefore, lead individuals to perceive themselves as being more similar to other members of their group (and less similar to outgroup members). This way, both types of cues should decrease the perceived social distance to the group $D_{i, j}$, making identification more attractive.

Overall, under the assumption that social status and social distance components are additively separable, group identification should become unequivocally more attractive in response to feedback about high relative performance. The common experience of winning should elevate the group's status and, at the same time, increase the perceived similarity among members so that identification increases.

Hypothesis 1. Being exposed to information about the ingroup's high relative performance, increases ingroup identification.

As argued above, the effect of learning about poor relative performance on identification is ambiguous. On the one hand, it impedes favorable intergroup comparisons thereby reducing group status. On the other hand, the common experience of losing together as a group may increase the perceived similarity to other members of the group. Exante it is unclear which of these two

\footnotetext{
${ }^{2}$ Note: One could also assume that individuals are already aware of the high relative performance of their group, so that additional information does not enhance $\left(\tilde{\pi}_{j}-\tilde{\pi}_{R(j)}\right)$. The additional information could then be interpreted as increasing the salience parameter $\sigma_{j}$.
} 
opposing effects dominates. Formally, it depends on the magnitudes of salience parameters $w$ and $\sigma$, whether group identification overall increases or decreases. The ambiguity of the overall effect is reflected in the following two alternative hypotheses.

Hypothesis 2. Being exposed to information about the ingroup's low relative performance, increases ingroup identification.

Hypothesis 3. Being exposed to information about the ingroup's low relative performance, decreases ingroup identification.

Finally, I briefly consider how ingroup identification may affect intergroup discrimination. The more individuals identify with a particular group, the more important this group is to their selfconcept (Turner et al. 1987, Roccas 2008, Postmes et al. 2013). Thus, when individuals identify more strongly with their group, they are increasingly motivated to behave in a way that helps to foster, preserve, and restore this group's positive distinctiveness in comparison to relevant outgroups (Hogg and Abrams 1988, Ellemers et al. 1999, Hornsey 2008). To formalize this notion, consider the following framework based on Chen and $\mathrm{Li}$ (2009). Individual $i$ 's utility function $V_{i}$, who is a member of group $j$, is defined as the weighted average of the intrinsic benefits derived from the material well-being of an ingroup member $\pi_{j}$ and the material well-being of an outgroup member $\pi_{k}$. Specifically, let the utility function be given by

$$
V_{i}\left(\pi_{j}, \pi_{k}\right)=I_{i j} \pi_{j}+\left(1-I_{i j}\right) \pi_{k}
$$

where the weighting factor $I_{i j}$ is equal to $i$ 's level of identification with the ingroup $j$ as specified above. This framework illustrates the notion, that an individual's concern for the well-being of an ingroup (outgroup) member increases (decreases) with the level of ingroup identification. ${ }^{3}$ Following this line of reasoning, I expect stronger ingroup identification to translate into stronger discrimination against the outgroup to which the ingroup is compared to. The following hypothesis summarizes these expectations.

Hypothesis 4. The level of discrimination against the outgroup to which the ingroup is compared to increases with the level of ingroup identification.

\footnotetext{
${ }^{3}$ Notably, this specification does not allow me to distinguish between motives of ingroup favoritism and outgroup derogation (see for Hewstone and Willis 2002). However, the framework is merely supposed to provide a formal overview of previous arguments, so that I abstract from this distinction at this point.
} 


\section{Experimental Design}

The primary objective of this paper is to test the previously derived hypotheses and thereby provide empirical evidence on a causal relationship between relative performance feedback on the group level and group identification. To do so is eminently challenging for various reasons.

For one, it is generally difficult to study causal relations in identification choices. This is due to imperfect control and knowledge about individuals' identification alternatives in a given situation, the endogeneity in group formation processes, heterogeneity of group stereotypes, and differences in instrumental values from identifying with a group.

In addition to these difficulties, there are issues specific to a group's relative performance that further impede studying a causal link. On the one hand, the group's performance is typically accompanied by current or future economic ramifications, which might affect social comparisons and thus identities. To investigate whether it is the exposure to information as such that affects identification choices and not their instrumental benefits, I need to detach relative performance of any economic consequences. On the other hand, a group's relative performance is virtually always endogenous, as it highly depends on its members' skills and abilities. There is even some evidence suggesting that individuals' willingness to exert efforts is positively correlated with group identification (Sen 2007, Chowdhury et al. 2016, Chen et al. 2017), such that, everything else being equal, a group whose members strongly identify are more likely to observe high relative performance. To circumvent these endogeneity concerns and to be able to identify causal relations, the relative performance needs to be randomly assigned.

I deal with these challenges by using a novel lab experiment. The experiment captures the following basic features. First, I use a minimal group setting to obtain tight control over group identities. Second, the group's relative performance does not have any current or future economic consequences. ${ }^{4}$ Third, whether a group performs well or poorly is effectively randomly assigned, yet not imposed by the experimenter, and individual contributions cannot be inferred.

All experimental sessions consisted of four different stages. In stage 1, subjects were randomly assigned into minimal groups and engaged in a series of group puzzles to make group memberships sufficiently meaningful. In stage 2 , groups competed with each other, whereby the outcome of competition, i.e., high and low relative performance, was effectively randomly assigned. Identification levels are elicited in stage 3. Finally, to identify behavioral consequences, individuals had to make a series of allocation decisions in stage 4. Sessions differed from each other concerning whether subjects received information about their group's relative performance immediately after the competition (treatment condition) or at the end of the experiment (control condition). As a result, there are three types of observations: control groups, winner groups, and loser groups.

\footnotetext{
${ }^{4}$ This feature of the experimental design additionally ensures that allocation choices in the second part of the experiment are not affected by previous gains.
} 


\subsection{Stage 1 - Group assignment and initial group enhancement}

In all sessions, individuals were randomly assigned to one of four minimal groups in which they would remain for the rest of the experiment. Each group consisted of three members. Groups were labeled by a geometric figure: triangle, circle, diamond, or square. To make the ingroup membership salient, the ingroup's symbol was displayed on-screen throughout the entire experiment except for stage 3, where individuals should report identification levels without being affected by seeing their own group's symbol. After individuals were privately informed about their group membership, they engaged in four rounds of unincentivized group puzzles, following a design by Hett et al. (2019). Puzzles were supposed to make group memberships sufficiently meaningful. ${ }^{5}$ Each quiz consisted of a set of four pictures, which can be connected by an unknown umbrella term. The objective was to guess the umbrella term. In every round subjects were given 60 seconds to discuss the solution with other members of their group by using a chat program. ${ }^{6}$ After the chat phase, participants entered their answers individually. At this point, subjects were not provided with a solution. ${ }^{7}$

\subsection{Stage 2 - Group competition and performance feedback}

In the second stage of the experiment, each group competed with one other group. This group will subsequently be referred to as comparison group. Subjects were privately informed about the label of the other group with which their group would compete. Groups then played five rounds of a modified version of the popular game of luck "Rock-paper-scissors". It was common knowledge that neither winning nor losing would have any consequences for the remainder of the experiment or experimental earnings. Subjects in all sessions were continually made aware of the identity of the contending group, by displaying its symbol on the screen throughout the five rounds. In every round subjects had to choose individually which of the symbols, "Rock", "Paper" or "Scissors", they want to play. Group members had no means of communicating with each other, such that coordination was impossible. After every group member had made a decision, a majority rule determined which symbol the group would play in the current round. In case of a tie, the symbol was randomly chosen with equal probabilities. Decisions of competing group pairs were then matched to determine the winner of a particular round following standard "Rock-paper-scissors" rules, except for the case

\footnotetext{
${ }^{5}$ Empirical evidence suggests that a study of identity in the lab may require an initial enhancement of group identities, for example through some joint activity (Chen and Li 2009, Chen and Chen 2011).

${ }^{6}$ Subjects were only allowed to discuss the solution of the group task in the chat phases. They were informed that a violation of this rule, e.g. discussing personal information, would lead to an expulsion from the rest of the experiment. Chat-logs show that individuals did not violate this rule.

${ }^{7}$ By not informing subjects about the actual solution and not giving them the chance to earn money, I exclude the possibility that individuals initially associate their group with successes or failures. Otherwise, I risk to bias the results concerning the exposure to information about the group's relative performance. Despite the evident lack of incentives and feedback, chat records show active engagement in solving the problems by participants in all sessions.
} 
where both groups chose the same symbol. In my experiment, the winner was determined by random draw if the chosen symbols coincided. ${ }^{8}$

For every round a group wins the corresponding group was given one point. Feedback was given after every single round. An updated scoreboard was displayed on screen throughout all five rounds. It is important to stress that participants were only informed about whether or not their group scored in a given round. They did not learn about the symbols chosen by their own or the rival group. The limited feedback had two purposes. First, it was supposed to avoid that individuals get frustrated with other ingroup members when their own symbol choice was overruled. Second, I ensured that symbol choices could not be contingent on the observed past play, making it impossible to develop particularly successful strategies and make inferences about cognitive skills of other participants.

After five rounds, groups with a higher score were explicitly announced to be the winner, i.e., exposed to information about high relative performance. Correspondingly, groups with the lower score were announced to have lost the contest, i.e., exposed to information about poor relative performance. Given this experimental procedure, the "Rock-paper-scissors" game has no pure strategy equilibrium, but only a mixed-strategy equilibrium under which all individuals play randomly. This implies that winner and loser groups are randomly assigned. ${ }^{9}$ By letting subjects actively decide what action to take, I tried to avoid creating the perception that winning and losing are the result of a lottery or imposed, as it would be the case when using a simple coin-flip. This way, winning and losing were supposed to appear more natural and self-involved.

Control sessions differed from the aforementioned treatment sessions only concerning provided feedback about the contest outcome. Participants in the control condition were withheld any information which would have given them the chance to infer competition outcomes during and after playing for five rounds. This is, they were neither provided information about the current score in a particular round nor did they eventually learn which group won or lost the contest. They only learned the outcome at the end of the experiment. ${ }^{10}$ Otherwise, the experimental set-up mirrored

\footnotetext{
8 The rules how different symbol choices relate to each other follow official definitions of the "World RPS Society": 6.0.1 - Rock: wins against scissors, loses to paper and stalemates against itself; 6.0.2 - Paper: wins against Rock, loses to scissors and stalemates against itself; 6.0.3 - Scissors: wins against paper, loses to rock and stalemates against itself. When both players chose the same symbol, the result is called a stalemate.

${ }^{9}$ To confirm that this was the case, I tested whether the probability of winning in a given round by choosing a particular symbol is significantly different from 0.5 , which should not be the case if groups randomize. Table 3 in the Appendix provides support for the claim that winner and loser groups are randomly assigned. It can be seen that, except for the first round, the chance of winning by choosing a particular symbol does not significantly differ from 0.5 .

${ }^{10}$ Participants in control sessions were asked to indicate whether they believed that their group was victorious. Almost $90 \%$ of subjects stated that they believed to have won. The belief over the contest outcome is not significantly correlated with the variables of interest, which is why I do not elaborate on elicited beliefs.
} 
treatment sessions in every detail to ensure perfect comparability. By comparing observations from control and treatment sessions, I am able to disentangle effects from competing and learning about the competition outcomes.

\subsection{Stage 3 - Elicitation of identification levels}

In the third stage, group identification levels were elicited. I used a slightly modified version of the Inclusion of the Other in the Self scale, which is a simple pictorial measure (Aron et al. 1992, Gächter et al. 2015) that has been successfully used to measure group identification in the psychology and economics literature on social identity before (see for example Tropp and Wright 2001, Rustagi and Veronesi 2016). Subjects were presented nine pairs of circles with different degrees of overlap.

For each pair of circles, one circle represented the respondent and the other one the group. Participants were asked to select the pair which best describes their relation to their group, resulting in a nine-point measure of identification levels (from 0 to 8). Subjects had to indicate the level of identification for the group they belonged, the comparison group against which the ingroup competed, and one of the two groups with which there was no interaction at all. The latter one was determined randomly and will further be referred to as neutral group.

\subsection{Stage 4 - Allocation choices}

In stage four, individuals had to make three allocation decisions, to measure subjects' extent of discrimination against the comparison group. I deployed experimental tasks that have been successfully used before and constitute a standard way to measure discriminatory tastes (Tajfel 1972, Tajfel 1974, Chen and Li 2009).

For each allocation decision, subjects were endowed with 200 monetary units (MU). These MU had to be split up between two other anonymous participants, of whom only group memberships were known. For two decisions, the first individual belonged to the same group as the decisionmaker, i.e., the ingroup. The second individual either belonged to the group against which the decision maker's group previously competed or the neutral-group for which I elicited identification levels. In a third allocation choice, $200 \mathrm{MU}$ had to be divided between a member of the comparison and neutral group.

In all decisions, individuals could neither gain nor lose personal income, i.e., material self-interest motives were absent. The default was set on an equal split to avoid priming subjects on a a discriminatory patterns. A deviation from the equal split captures the most simple and natural form of unequal treatment of different individuals solely based on their group membership. ${ }^{11}$

\footnotetext{
11 These allocation games are often used in minimal group studies in the social psychology literature. In these studies, psychologists consistently find the subjects' tendencies to allocate significantly bigger shares to a member of their ingroup, showing that categorization suffices to generate intergroup discrimination (among others Tajfel 1979, Tajfel and Billig 1974)
} 
In treatment sessions where individuals had already learned about competition outcomes, a small picture was displayed on the screen, highlighting who won and who lost. In baseline sessions where the outcome was not revealed yet, a small picture only depicted the symbol of the adversary-group. In that way, baseline participants were merely withheld information about the contest outcome, while the identity of the former competitor was also made salient.

At the end of the experiment, individuals were shown their private income from the experiment and informed about solutions of the group quizzes from stage 1. Payoff procedures followed Chen and $\mathrm{Li}$ (2009). In particular, individuals were informed that they would be randomly matched with another participant and that one of this person's relevant allocation choices would be randomly selected to compute payoffs. Finally, before being paid out, participants were asked to fill out a post-experimental questionnaire, containing questions about demographics.

\subsection{Experimental summary}

I conducted nine sessions with a total of 216 participants. Three sessions were control and the remaining six sessions were treatment conditions. The experiment took place at the Frankfurter Laboratory for Experimental Economic Research (FLEX) in the first two weeks of February 2017. Subjects were students from the Goethe University Frankfurt. The experiment was programmed using z-Tree (Fischbacher 2007). Each session consisted of 24 participants and lasted about 15 to 20 minutes. Per 100 MU earned in the experiment, individuals received a payment of 1.5 Euro. Additionally, participants received a show-up fee of 4.5 Euro. On average individuals earned 6.53 Euro. Instructions were split into two parts and distributed right before stage 1 and 2 started. ${ }^{12}$ By doing so, I ensured that subjects could not discuss and coordinate on payoff relevant decisions in the chat phases in stage 1 .

\section{Results}

The results will be presented in three parts. First, I depict how exposure to information about the ingroup's relative performance affects group identification levels, i.e., I test hypotheses 1,2 , and 3. The second part will be devoted to an analysis of how discriminatory patterns, in particular outgroup derogation, change in response to being exposed to information of the ingroup's relative performance. In the last step, I investigate causal relations between the strength of ingroup identification and changes in outgroup derogation to test hypothesis 4 .

In the experiment, I elicited the self-reported identification of participants with their ingroup and a neutral group with which they had no interaction whatsoever. ${ }^{13}$ The latter one will serve as

\footnotetext{
${ }^{12}$ With respect to the elicitation of identification levels, instructions were merely displayed on screen.
}

${ }^{13}$ Note: The indicated level of identification with the comparison group is included as a control variable in regressions analyses on allocation choices shown in table 2. The level of identification is found to be insignificant across all specifications. 
a within subject baseline of identification with groups in general. Specifically, I subtract reported levels of identification with the neutral group from reported levels of ingroup identification. This difference is used as the measure for the level of ingroup identification throughout the analyses. To identify the impact of an exposure to information about relative group performance on the strength of identification with the ingroup, I compare the measure across the control, winner, and loser conditions. In other words, I pursue a difference-in-difference approach.

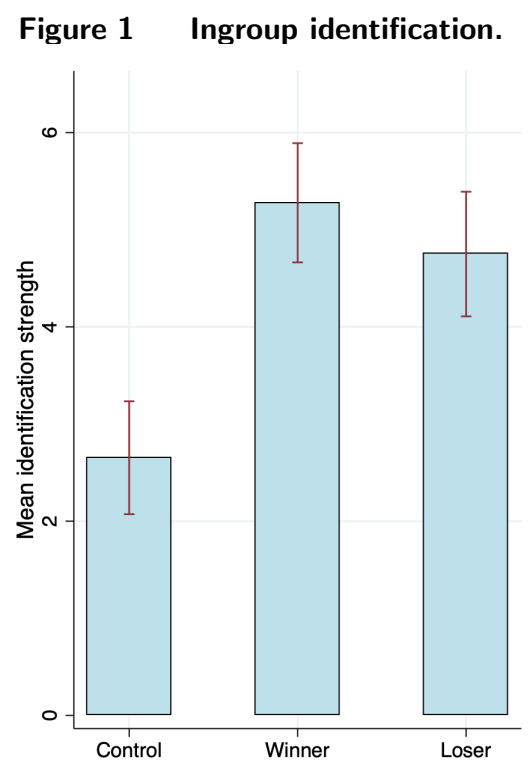

Note. The average level of identification levels and $95 \%$ confidence intervals are displayed. The figure contains measures for control, winner, and loser conditions.

Figure 1 plots individuals' strength of ingroup identification. Displayed bars represent average levels of participants who were not informed about their group's performance (control), participants who were informed that their group's relative performance was high (winner), and participants who were informed that their group's relative performance was poor (loser).

Figure 1 indicates that the strength of ingroup identification is sensitive to being exposed to information about the group's relative performance. In control sessions, participants' average level of ingroup identification amounts to 2.65. Individuals who were informed that their group won reported an average group identification of 5.28. The difference constitutes an increase of $98.5 \%$. Average group identification levels for individuals who learned that their group performed poorly amount to 4.75. In comparison to the control treatment, this is an increase of more than $79 \%$. A comparison of the levels of group identification between cases where individuals learned that their group lost and won, shows that the difference in identification levels amounts to 0.53. 
Table 1 Ingroup identification.

\begin{tabular}{lcc}
\hline Dependent variable: & $(1)$ & $(2)$ \\
Ingroup identification & & \\
\hline Winner & $\begin{array}{c}2.625^{* * *} \\
(0.454)\end{array}$ & $\begin{array}{c}2.612^{* * *} \\
(0.463)\end{array}$ \\
& $2.097^{* * *}$ & $2.128^{* * *}$ \\
Loser & $(0.380)$ & $(0.392)$ \\
& & \\
Constant & $2.653^{* * *}$ & $3.856^{* *}$ \\
& $(0.176)$ & $(1.615)$ \\
\hline Controls & No & Yes \\
\hline $\mathrm{N}$ & 216 & 216 \\
$R^{2}$ & 0.161 & 0.167 \\
$\mathrm{p}$ & 0.000 & 0.000 \\
\hline \hline
\end{tabular}

Results of OLS regressions are reported. The level of ingroup identification serves as the dependent variable. Winner and loser are treatment dummy variables. Choices in control conditions serve as the reference category. Control variables include subjects' gender, age, and graduation status. Robust standard errors are clustered at the group level and depicted in parentheses. Significances are denoted as ${ }^{*} p<0.1,{ }^{* *} p<0.05,{ }^{* * *}$ $p<0.01$.

Regression results reported in table 1 corroborate these observations statistically. In columns (1) and (2) I report estimates from OLS regressions, where the strength of identification serves as the dependent variable. The explanatory variables Winner, and Loser are dummy variables, referring to corresponding information exposures in treatment sessions. Observations from control sessions serve as the reference category. In column (2), I additionally include participants' gender, age, and graduation status as individual level controls. Because subjects make their decisions as part of a group that competed, I cluster robust standard errors at the group level.

The estimated coefficients for treatment dummy variables in column (1) show that observed differences in ingroup identification levels between control and winner groups, as well as control and loser groups, are highly statistically significant. A Wald test reveals that the difference between winner and loser groups is not statistically significant at any conventional level $(p<0.316)$. As can be seen from column (2), results are robust to the inclusion of individual-level control variables. Overall the findings show that both the exposure to information about the high and poor relative performance of the ingroup foster ingroup identification. Notably, the difference in effect sizes is statistically insignificant. Overall, the findings are in line with hypotheses 1 and 2 and can be summarized as follows. 
RESULT 1: The level of ingroup identification increases in response to being exposed to information about the group's relative performance. Identification levels increase similarly in both cases, when subjects learn that the group performed well or poorly.

Next, I explore participants' decisions where they had to split up 200 monetary units between a member of the ingroup and a member of either the comparison group or the neutral group. ${ }^{14}$ Given the nature of the task, any unequal allocation reflects a taste for group based discrimination. In general, literature in social psychology distinguishes between two different motives driving ingroupoutgroup discrimination: (i) ingroup favoritism and (ii) outgroup derogation (Brewer 1999, Mullen et al. 1992, Hewestone et al. 2002). Ingroup favoritism refers to discrimination motivated by a desire to make the ingroup better off. Outgroup derogation, on the other hand, is an unequal treatment based on the intention to hurt the outgroup, i.e., hostile intend. The focus of this paper lies on identifying whether exposure to information about the ingroup's relative performance affects the latter type, hence hostile discrimination that is specifically intended to hurt members of the comparison group.

To this end, I subtract the number of monetary units individuals assigned to the member of their own group, given an affiliate of the neutral group was affected, from the number of monetary units allocated to the ingroup member when a member of the comparison group was affected. Considering that participants in control and treatment conditions both had not interacted with neutral group members at all, there is no reason to belief that derogation against these individuals changed. In fact, differences between allocation choices where monetary units had to be divided between an ingroup and neutral group member in control and treatment conditions are statistically insignificant. ${ }^{15}$ At the same time, the degree of ingroup favoritism should not vary across allocation choices where ingroup members and members of different outgroups are affected, as it is a (temporary) stable preference to favor ingroup members over members of other groups to a certain extent (Hewestone et al. 2002). Under these two reasonable assumptions, subtracting the two measures in the aforementioned fashion and comparing the resulting variable across control

\footnotetext{
${ }^{14}$ Summary statistics on participants' choices can be found in table 4 in the appendix. It can be seen that individuals generally divide monetary units in a way substantially benefiting the subject with whom they share a group. This is likewise true for both allocation choices and across control, loser, and winner groups. Averaged across all participants, an individual assigns 139.7 MUs to the ingroup member if an affiliate of the comparison group is affected by the decision, and 135.5 MUs if it is a member of the neutral group who is affected. On an individual level, I find about a third of participants to make a fair split of monetary units in both allocation choices. This is true for control, winner, and loser groups alike (respectively 0.306, 0.333, 0.292). This observation mirrors results from previous studies which observe people exhibiting a taste for discrimination between ingroup, and outgroup members (Tajfel 1972, Chen and Li 2009, Chen and Chen 2011, Hett et al. 2019).

${ }^{15}$ Results of corresponding regression analyses can be found in table 5 in the appendix.
} 
and treatment conditions, effectively isolates changes in the derogation against the comparison group that are driven by exposure to information about the ingroup's relative performance.

Figure 2 depicts participants' additional willingness to hurt members of the comparison relative to the neutral group. Negative values indicate, that subjects allocate relatively more monetary units to a member of the comparison group than to a member of a neutral group. This is, participants discriminate less against the group of comparison than they do against a neutral group. A value of 0 indicates that people do not treat members of the comparison and neutral group differently. Finally, a positive value implies that people have a stronger preference to hurt members of the comparison group than members of a neutral group.

Figure 2 Hostile outgroup discrimination.

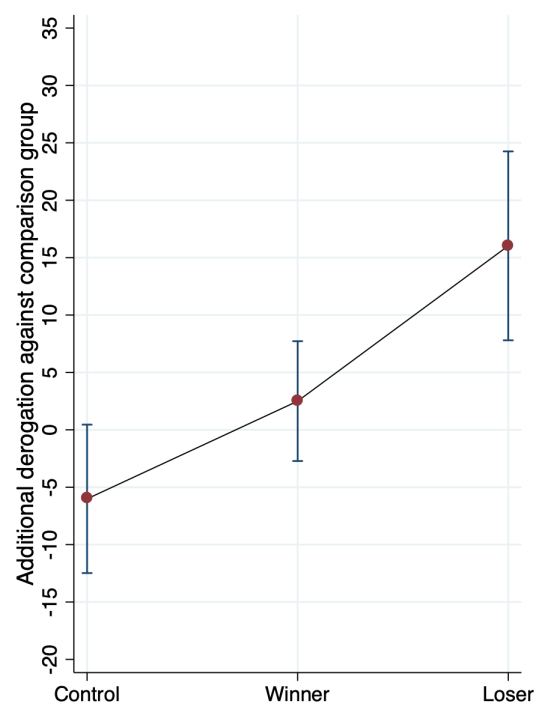

Note. The average level of additional derogation against comparison relative to neutral groups together with $95 \%$ confidence intervals is displayed. Outgroup derogation refers to discrimination specifically intended to hurt members of these groups. The figure contains measures for control, winner, and loser conditions.

Figure 2 suggests that participants in the control condition treat members of the comparison group more favorably than members of a neutral group. On average they assign 6.01 monetary units more to an affiliate of the comparison group. After exposure to information about the ingroup's relative performance, participants' willingness to hurt members of the comparison group appears to increase. In comparison to the control condition, this is an increase of more than 8 monetary units. Participants who learned about the ingroup's poor relative performance discriminated more against members of the comparison group than participants who belong to the neutral group. Specifically, former subjects received 16.03 units less. Relative to the control and winner condition, 
Table 2 Hostile discrimination against comparison group.

\begin{tabular}{lcccc}
\hline \hline $\begin{array}{l}\text { Dependent variable: } \\
\text { Comparison group derogation }\end{array}$ & $(1)$ & $(2)$ & $(3)$ & $(4)$ \\
\hline Winner & $8.514^{* *}$ & $7.020^{*}$ & 5.838 & 3.974 \\
& $(3.953)$ & $(3.687)$ & $(3.685)$ & $(3.307)$ \\
Loser & & & & \\
& $22.042^{* * *}$ & $20.304^{* * *}$ & $19.904^{* * *}$ & $18.069^{* * *}$ \\
& $(4.250)$ & $(4.337)$ & $(4.474)$ & $(4.459)$ \\
Ingroup identification & & & & \\
& & & $\left(0.019^{*}\right.$ & $1.212^{* *}$ \\
& & & & $(0.495)$ \\
Constant & $-6.014^{* *}$ & -27.652 & $-8.718^{* *}$ & -33.390 \\
& $(2.538)$ & $(25.241)$ & $(3.024)$ & $(24.814)$ \\
\hline Controls & No & Yes & No & Yes \\
\hline $\mathrm{N}$ & 216 & 216 & 216 & 216 \\
$R^{2}$ & 0.092 & 0.116 & 0.100 & 0.127 \\
$\mathrm{p}$ & 0.000 & 0.000 & 0.001 & 0.001 \\
\hline \hline
\end{tabular}

Results of OLS regressions are reported. The level of additional comparison group derogation serves as the dependent variable. Outgroup derogation refers to discrimination specifically intended to hurt members of these groups. Winner and loser are treatment dummy variables. Choices in control conditions serve as the reference category. Control variables include subjects' level of identification with the comparison group, gender, age, and graduation status. Robust standard errors are clustered at the group level and depicted in parentheses. Significances are denoted as ${ }^{*} p<0.1,{ }^{* *} p<0.05,{ }^{* * *} p<0.01$.

this constitutes a difference in derogation against the comparison group respectively by 22 and 14 monetary units.

Regression analyses reported in columns (1) and (2) of table 2 show that the increase in participants' willingness to hurt members of the comparison group after learning the ingroup's relative performance is significant for both cases, yet more pronounced and only robust when people learn that the ingroup lost. All columns in table 2 depict OLS regression results, where participants' additional derogation against the comparison group is the dependent variable. The variables Winner and Loser are treatment dummies. Observations from control sessions serve as the reference category. Controls in columns (2) and (4) include participants' level of identification with the comparison group, gender, age, and graduation status. Robust standard errors are clustered at the group level.

Estimated coefficients in column (1) show that the increase in comparison group derogation after being informed about a victory of the ingroup is significant. However, when including additional controls in column (2) the magnitude and statistical significance of the estimate decrease. In contrast, the increase in derogation against the group of comparison after learning that the ingroup lost is found to be highly significant throughout all regressions. Additionally, a Wald test corroborates that exposure to information about a high and low relative performance of the ingroup incites heterogeneous behavioral responses $(p<0.011)$. 
RESULT 2: Being exposed to information about the ingroup's relative performance increases comparison group derogation. The effect observed for learning about a low relative performance is significantly stronger.

The remaining question is, to what extent variation in the level of ingroup identification can account for behavioral heterogeneities, i.e., whether or not hypothesis 4 holds. Figure 3 plots subjects' additional derogation against the comparison group conditional on their level of ingroup identification. Straight lines represent fitted values.

Figure 3 Ingroup identification and hostile discrimination.

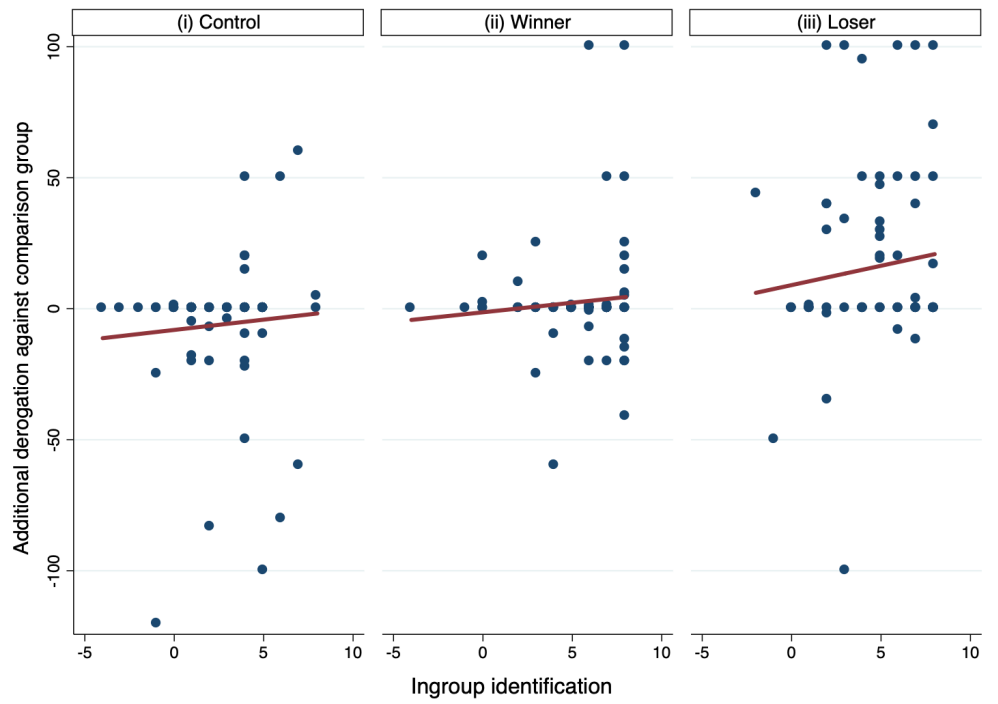

Note. Subjects' additional derogation against the comparison group in relation to their level of ingroup identification is depicted. Straight lines represent fitted values. From left to right, panels show results for the (i) control, (ii) winner, and (iii) loser condition.

Displayed results suggest that there exists a positive relationship between the level of ingroup identification and the level of additional discrimination against the comparison group. Fitted values in all three panels appear to possess a similarly positive slope, i.e., in all conditions, a marginal increase in the level of ingroup identification seems to translate into a similar increase in additional derogation against the comparison group. Notably, results for the loser condition further indicate the presence of a level effect. In comparison to panels (i) and (ii), the additional derogation against the comparison group is higher for all levels of ingroup identification in panel (iii).

Overall, observed patterns are in support of hypothesis 4 and also provide a plausible explanation for previously illustrated results. The average subject in winner and loser conditions exhibits stronger ingroup identification than the counterpart in the control condition. This translates into 
higher levels of additional comparison group derogation. The observed heterogeneity concerning discrimination between winner and loser conditions appears to result from a level effect that is only present in the latter one.

Results from regression analyses shown in columns (3) and (4) in table 2 corroborate this explanation statistically. In contrast to the first two columns, columns (3) and (4) additionally include the level of ingroup identification as an explanatory variable. ${ }^{16}$ According to the results, an increase in ingroup identification by one unit increases the level of additional derogation against the comparison group by one MU. It can be seen that the inclusion of ingroup identification leads to a reduction in the magnitude and significance of treatment dummy variables, suggesting that treatment effects are partially driven by enhanced identification levels. The decrease is particularly pronounced for the variable Winner, which is insignificant once I control for ingroup identification. Hence, differences in comparison group derogation we observe between control and winner conditions appear to be mainly driven by enhanced identification levels. The Loser dummy variable, in contrast remains significant even though identification effects can be similarly found. This observation corroborates the impression that the exposure to information about a poor relative performance does not only enhance comparison group derogation indirectly by increasing ingroup identification, but additionally directly via some level effect.

RESULT 3: The increase ingroup identification, caused by the exposure to performance feedback, can partially account for the increase in derogation against the comparison group. Learning about a poor relative performance additionally evokes a level effect enhancing comparison group derogation.

\section{Discussion and Conclusion}

The current paper deploys a lab experiment to study causal effects of being exposed to information about the ingroup's relative performance on group identification and thereby hostility against the group to which the ingroup is compared. My results from the experiment shed light on a causal link between exposure to information about ingroup performance and intergroup hostilities, which are in line with predictions I derive from social identity theory (Tajfel and Turner 1979, Shayo 2009, Chen and Li 2009).

I find both being informed about high and low relative performance similarly foster ingroup identification. Following the previously derived theoretical framework, this observation suggests that

${ }^{16}$ Note: The application of an instrumental variable approach to estimate local average treatment effects is impossible because the data suggests that the exclusion restriction is violated. Specifically, I would need to assume that if the level of identification could be held constant, feedback on the ingroup's relative performance would not lead to stronger discrimination against the comparison group. Evidence for a level effect, however, strongly suggests that such a direct relation between information exposure and discrimination exists. 
the impact on perceived social distances within groups is stronger than social status consequences. The information about winning and losing together as a group may be perceived as a unit-forming factor that creates a sense of us versus them among ingroup members. My findings would suggest that this changed perception is more important to people than the nature of the information as such.

In line with previous findings in the literature (see for example Abrams and Hogg 1988, Chen and Li 2009, Kranton et al. 2016), I observe the strength of identification to constitute a source of variation in individual behavior. To the best of my knowledge, my study is the first to document that enhanced levels of ingroup identification can partially account for increases in hostile discrimination against the comparison group. However, while the exposure to both types of information similarly increases ingroup identification, learning about a poor relative performance appears to invoke stronger hostility against the comparison group.

This begs the questions how one can account for these behavioral differences? One possible explanation is twofold. On the one hand, the positive status effect from being informed that the ingroup won, may create a Noblesse oblige effect, which refers to high status individuals' higher propensity to comply with broad social norms such as egalitarian concerns (Homans 1950). Previous empirical work has documented a positive relation between status and pro-social behavior (see for example Henry et al. 2014). Hence, winning as such, through increasing the ingroup's status, may counteract the increase in discrimination caused by stronger ingroup identification. On the other hand, losing as such may incite a desire for retribution, which motivates additional hostility against the comparison group. This interpretation is in line with previous studies who document that individuals experience an intrinsic depression when they loose (Delgado et al. 2008) and reduce their pro-social behavior toward others (Buser and Dreber 2016, Kidd et al. 2013). Even though it is the ingroup that loses and not the independent individual, it appears plausible that similar cognitive reactions encourage additional intergroup discrimination. A regression analysis of the allocation choice where units had to be divided between two members of the comparison and neutral group, provides some support for this notion (see Table 5 in the Appendix). While not statistically significant, the coefficients for winner and loser dummy variables are respectively positive and negative, while the estimate for ingroup identification is negative. This suggests that strengthened ingroup identification as such increases discrimination targeted against the outgroup, while direct effects from learning about a high (low) relative performance of the ingroup mitigate (reinforce) these discriminatory patterns.

Overall, my results shed light on a potential channel through which social media may contribute to social fragmentation and polarization. My findings indicate that the dissemination of information about the relative performance of social groups as such may shape identification with 
these groups and subsequently intergroup discrimination, which can contribute to polarization (Weisel 2016). This may be one of the mechanisms that underlie findings by Alcott et al. (2020) and Gentzkow (2016), who provide evidence suggesting that social media can increase political polarization and exacerbate social divides along partisan lines.

\section{Appendix A. Supplementary Material}

\begin{tabular}{|c|c|c|c|}
\hline \multirow[b]{3}{*}{ \# Round } & \multicolumn{3}{|c|}{$\begin{array}{l}\text { Empirical choices in the } \\
\text {-paper-scissors" game. }\end{array}$} \\
\hline & \multicolumn{3}{|c|}{$\begin{array}{c}\text { Share of groups } \\
\text { who won by choosing }\end{array}$} \\
\hline & Rock & Paper & Scissors \\
\hline \multirow[t]{2}{*}{1} & $45 \%$ & $79 \%$ ** & $0 \%$ ** \\
\hline & $\mathrm{Obs}=29$ & $\mathrm{Obs}=14$ & $\mathrm{Obs}=5$ \\
\hline \multirow[t]{2}{*}{2} & $50 \%$ & $50 \%$ & $50 \%$ \\
\hline & $\mathrm{Obs}=18$ & $\mathrm{Obs}=12$ & $\mathrm{Obs}=18$ \\
\hline \multirow[t]{2}{*}{3} & $65 \%$ & $44 \%$ & $40 \%$ \\
\hline & $\mathrm{Obs}=17$ & $\mathrm{Obs}=16$ & $\mathrm{Obs}=15$ \\
\hline \multirow[t]{2}{*}{4} & $31 \%$ & $60 \%$ & $58 \%$ \\
\hline & $\mathrm{Obs}=16$ & $\mathrm{Obs}=20$ & $\mathrm{Obs}=12$ \\
\hline \multirow[t]{2}{*}{5} & $52 \%$ & $46 \%$ & $50 \%$ \\
\hline & $\mathrm{Obs}=13$ & $\mathrm{Obs}=21$ & $\mathrm{Obs}=14$ \\
\hline
\end{tabular}

Empirical probabilities that a group won a round of the "Rock-paper-scissors" game, conditional on choosing a particular symbol are depicted. Values only refer to sessions in which individuals were informed about the competition outcomes. ${ }^{*} p<$ $0.1,{ }^{* *} p<0.05,{ }^{* * *} p<0.01$ respectively indicate whether the depicted share is significantly different from 0.5 in a Wilcoxon signed-rank test. 
Table 4 Summary statistics allocation choices.

\begin{tabular}{|c|c|c|c|}
\hline & \multicolumn{3}{|c|}{ Allocation choices } \\
\hline & (i) Ingroup \& & (ii) Ingroup \& & (i)-(ii)] Ourgroup \\
\hline & Comparison-group: & Neutral-group: & derogation \\
\hline & Mean MUs & Mean MUs & against \\
\hline & given to ingroup & given to ingroup & comparison group \\
\hline \multirow[t]{2}{*}{ Control } & 133.1 & 139.1 & -6.01 \\
\hline & $(43.326)$ & $(45.41)$ & $(27.517)$ \\
\hline \multirow[t]{2}{*}{ Winner } & 137.1 & 134.6 & 2.5 \\
\hline & $(39.955)$ & $(39.999)$ & $(22.208)$ \\
\hline \multirow[t]{2}{*}{ Loser } & 148.9 & 132.9 & 16.03 \\
\hline & $(41.959)$ & $(44.131)$ & $(35.015)$ \\
\hline
\end{tabular}

Summary statistics on allocation choices are depicted. Values displayed in parentheses are standard errors.

Table 5 Allocation game choices where MUs were divided between an ingroup and neutral group member.

\begin{tabular}{lcc}
\hline \hline $\begin{array}{l}\text { Dependent variable: } \\
\text { MU assigned to ingroup member }\end{array}$ & $(1)$ & $(2)$ \\
\hline Winner & -4.486 & -1.791 \\
& $(7.009)$ & $(7.688)$ \\
& & \\
Loser & -6.250 & -3.206 \\
& $(6.599)$ & $(6.704)$ \\
Constant & & \\
& $139.111^{* * *}$ & $130.578^{* * *}$ \\
Controls & $(4.450)$ & $(18.569)$ \\
\hline $\mathrm{N}$ & $\mathrm{No}$ & Yes \\
$R^{2}$ & 216 & 216 \\
$\mathrm{p}$ & 0.004 & 0.053 \\
\hline \hline
\end{tabular}

Results of OLS regressions are reported. The dependent variable is the number of MU participants assigned to an ingroup member in the allocation choice between an ingroup and neutral group member. Winner and loser are treatment dummy variables. Choices in control conditions serve as the reference category. Control variables include subjects' gender, age, and graduation status. Robust standard errors are clustered at the group level and depicted in parentheses. Significances are denoted as ${ }^{*} p<0.1,{ }^{* *} p<0.05,{ }^{* * *} p<0.01$. 
Table 6 Allocation game choices where MUs were divided between a comparison and neutral group member.

\begin{tabular}{lcccc}
\hline \hline Dependent variable: & $(1)$ & $(2)$ & $(3)$ & $(4)$ \\
MU assigned to comparison group member & & & & \\
\hline Winner & 1.278 & 2.172 & 3.995 & 4.333 \\
& $(5.945)$ & $(6.156)$ & $(6.440)$ & $(6.861)$ \\
Loser & $-11.583^{*}$ & $-11.775^{*}$ & -9.413 & -10.190 \\
& $(6.402)$ & $(6.151)$ & $(7.105)$ & $(6.920)$ \\
Ingroup identification & & & & \\
& & & -1.035 & -0.859 \\
Constant & & & $(1.021)$ & $(1.132)$ \\
& $101.486^{* * *}$ & $97.917^{* * *}$ & $104.232^{* * *}$ & $101.987^{* * *}$ \\
Controls & $(5.093)$ & $(21.925)$ & $(5.760)$ & $(22.169)$ \\
\hline $\mathrm{N}$ & No & Yes & No & Yes \\
$R^{2}$ & 216 & 216 & 216 & 216 \\
$\mathrm{p}$ & 0.025 & 0.050 & 0.030 & 0.053 \\
\hline \hline
\end{tabular}

Results of OLS regressions are reported. The level of monetary units given to the member of the comparison group, when dividing 200 monetary units between a comparison and neutral group member, serves as the dependent variable. Winner and loser are treatment dummy variables. Choices in control conditions serve as the reference category. Control variables include subjects' level of identification with the comparison group, gender, age, and graduation status. Robust standard errors are clustered at the group level and depicted in parentheses. Significances are denoted as ${ }^{*} p<0.1,{ }^{* *} p<0.05,{ }^{* * *} p<0.01$. 


\section{Appendix B. Experimental Instructions}

\section{General Information}

Thank you very much for your participation in today's experiment. You will find all necessary information in the instructions. Please read them carefully.

We guarantee that at no time will any other experiment participant be informed of your identity. It is also not impossible for the experimenters to assign identities.

All information provided by you will be treated confidentially and will not be passed on to third parties. The data is used exclusively for scientific purposes.

During the experiment we ask you not to communicate with other participants unless requested. Please also switch off your mobile phone. If you have a question, please raise your hand. We will then come to you and answer your question personally.

During this experiment you can collect points. The number of points you receive depends on your and your fellow players' decisions. You must enter your decisions on the screen. At the end of the experiment, your total collected points will be converted into Euros and paid out. The following applies:

\section{0 points $=1.50$ Euro}

The study is divided into several stages, within each of which you can make decisions and collect points.

In addition to the points you can collect in the different levels, you will receive an independent participation fee of 300 points. 
Specific Information

\section{Group memberships}

At the beginning of the study, all participants are randomly divided into different groups with a total of three members each. There is the group triangle, the group square, the group circle and the group diamond. Each participant becomes a member of one of the four groups. For the whole course of the experiment you will be a member of this group.

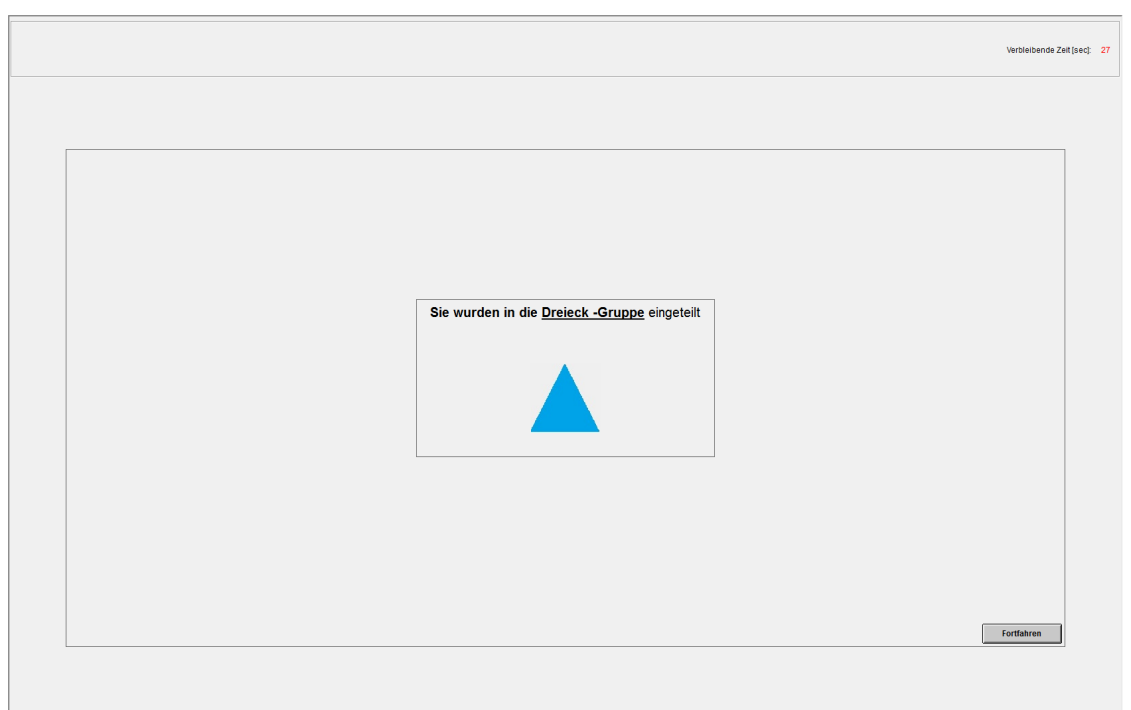




\section{$\underline{\text { Stage } 1}$}

In stage 1 you will receive a series of picture puzzles that you will discuss within your respective group. Each picture puzzle consists of four individual pictures, which can be connected by a certain word. The goal is to find out this word.

You have to solve four picture puzzles with the members of your group. You have 60 seconds for each picture puzzle to consult with the corresponding members of your group via chat window. The messages you enter can only be read by the members of your group. On the other hand, you can also only read the messages written by the members of your group. After the consultation time has expired, you have 15 seconds to enter your personal answer.

Please note: You are allowed to discuss all kinds of topics in the chat window. However, you are strictly forbidden to reveal your identity in any way. Any violation of this rule will result in exclusion from the rest of the experiment.

If you have no further questions, please press "Continue".

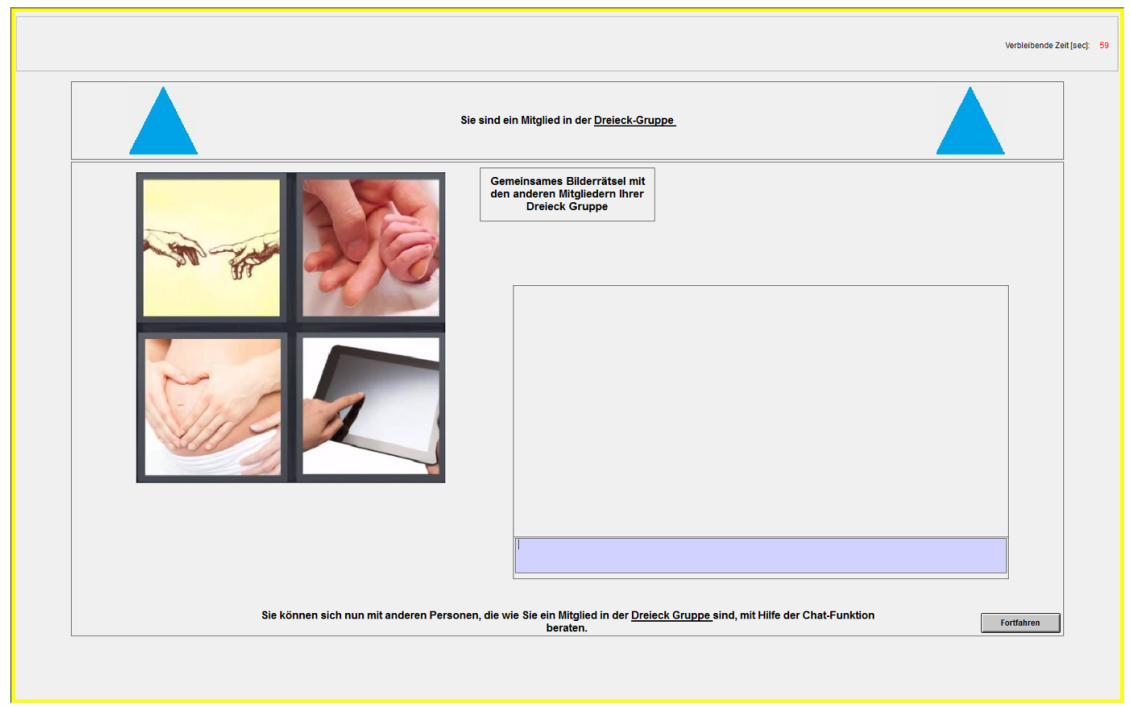




\section{Stage 2: Treatment}

In the second stage of the experiment, you and your group compete against another randomly selected group in a contest.

You and your group members compete against the other group in the game "Scissors-StonePaper". The first group to reach 3 points wins. Your group gets one point if the symbol chosen by your group beats the chosen symbol of the opposing group. You can select the symbols "scissors", "stone" or "paper". The following rules apply:

\section{i. Scissors beats paper \\ ii. Paper beats stone \\ iii. Rock beats paper}

In the event that both groups select the same symbol in a round, a draw will determine which of the two rival groups in that round receives one point. The probability that one group receives the point is $50 \%$ for each group.

The selection of the symbol that a group plays in a round is made by majority vote. Each group member decides individually which symbol to play. In each round you have 15 seconds to select one of the three symbols. Then the symbol that has received the most votes within the group is determined and played. In the event that each symbol receives the same number of votes, one of the three symbols is randomly selected and played with equal probability.

As soon as one of the two groups in the competition has reached 3 points, the game is over.

After the end of the competition, you will be asked to indicate how strongly you feel you belong to different groups. Neither this information nor the outcome of the competition will affect the rest of the experiment or your ability to earn money within the experiment. 

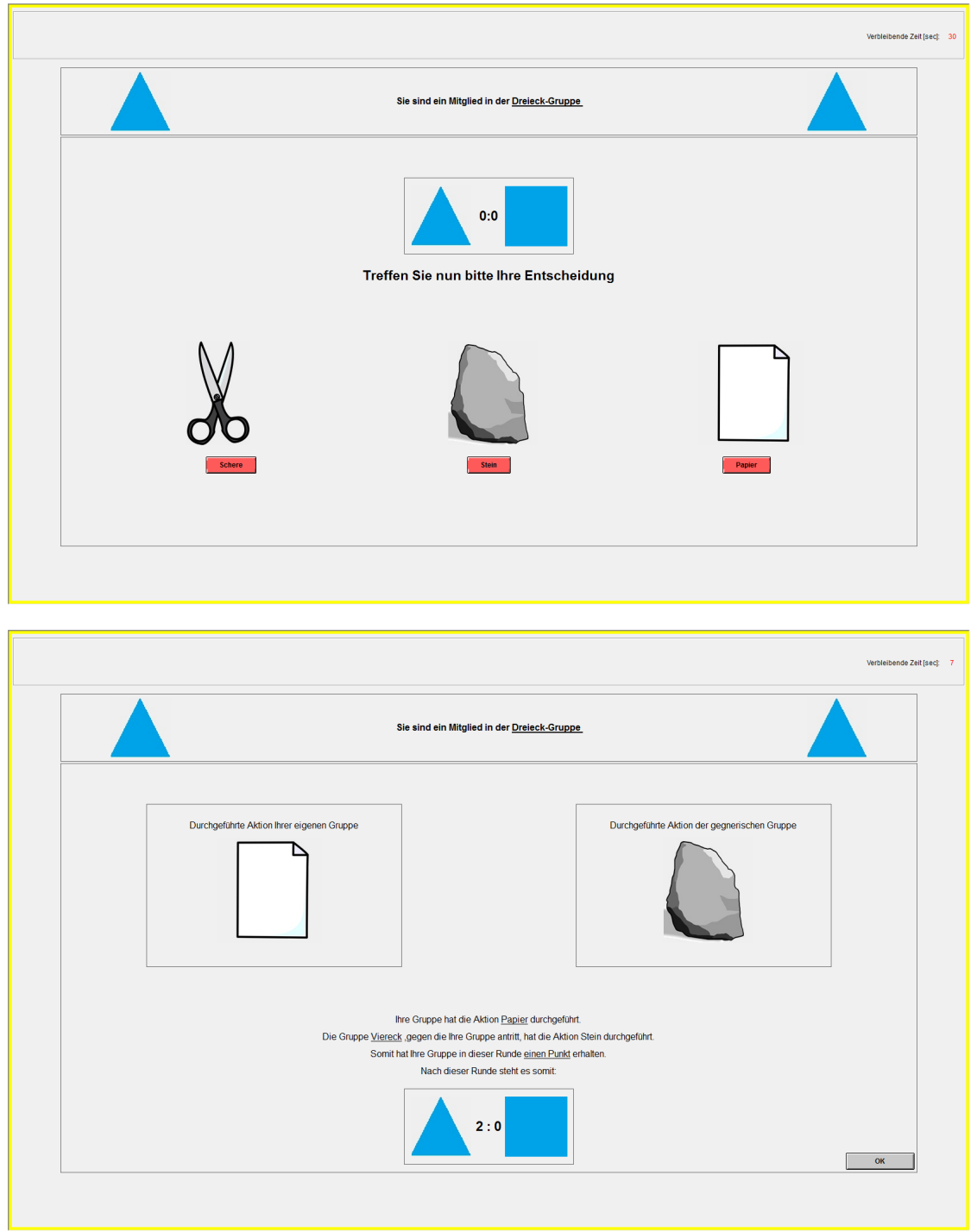


\section{Stage 2: Control}

In the second stage of the experiment, you and your group compete against another randomly selected group in a contest.

You and your group members compete against the other group in the game "Scissors-StonePaper". There will be 3 to 5 rounds. The exact number of rounds is determined randomly. The group with the most points at the end of the game wins. Your group gets one point if the symbol chosen by your group beats the chosen symbol of the opponent's group. The symbols "scissors", "stone" or "paper" can be selected. The following rules apply:

\section{i. Scissors beats paper \\ ii. Paper beats stone \\ iii. Rock beats paper}

In the event that both groups select the same symbol in a round, a draw will determine which of the two rival groups in that round receives one point. The probability that one group receives the point is $50 \%$ for each group.

The selection of the symbol that a group plays in a round is made by majority vote. Each group member decides individually which symbol to play. In each round you have 15 seconds to select one of the three symbols. Then the symbol that has received the most votes within the group is determined and played. In the event that each symbol receives the same number of votes, one of the three symbols is randomly selected and played with equal probability. You will find out which group won at the end of the experiment.

After the end of the competition, you will be asked to indicate how strongly you feel you belong to different groups. Neither this information, nor the outcome of the competition, which is unknown to you at this point, will have any influence on the further course of the experiment, or your ability to earn money within the experiment.

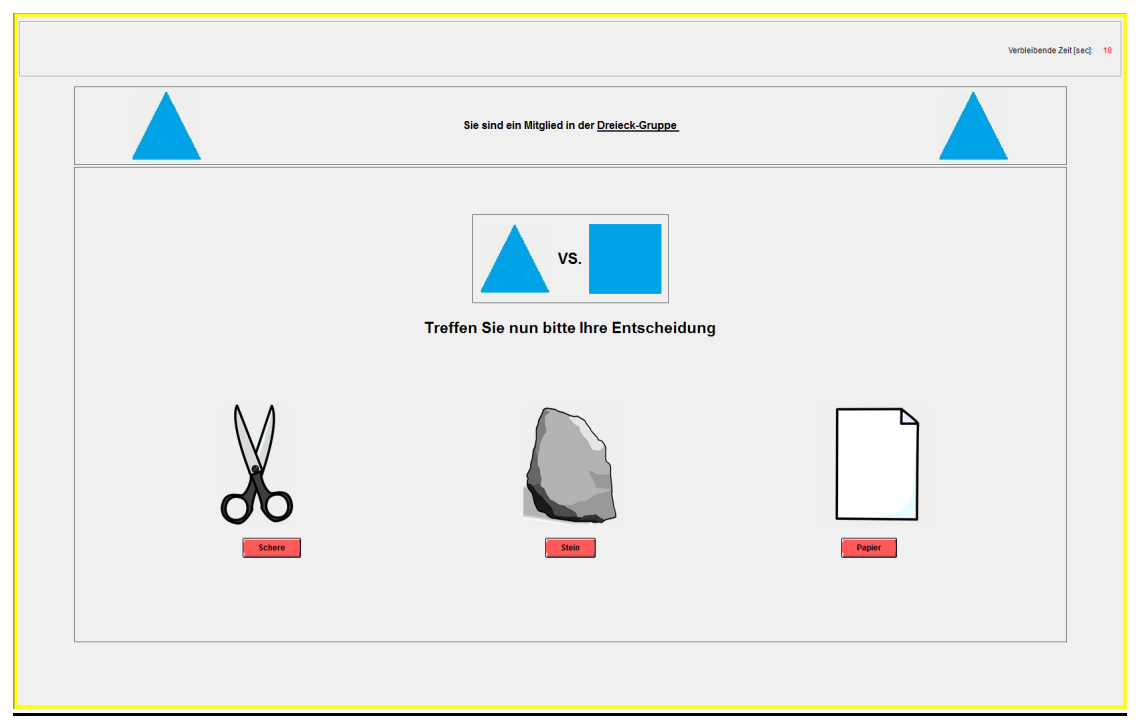




\section{$\underline{\text { Stage } 3}$}

In the third stage of the experiment you have to make decisions on how to split 200 points between two randomly selected participants. The income of the participants corresponds to the number of points you assign.

Before you make your decision, you will receive information about the group memberships of the selected participants. You only now whether or not the two participants are each a group member of your group.

You will be confronted with different scenarios. The scenarios differ in that you have to decide how to divide the 200 points for different participants with different group memberships.

At the end of the experiment, one of your decisions will be randomly selected and implemented.

Your personal income from stage 3 corresponds to the amount that another participant, to whom you are randomly assigned, has sent you.

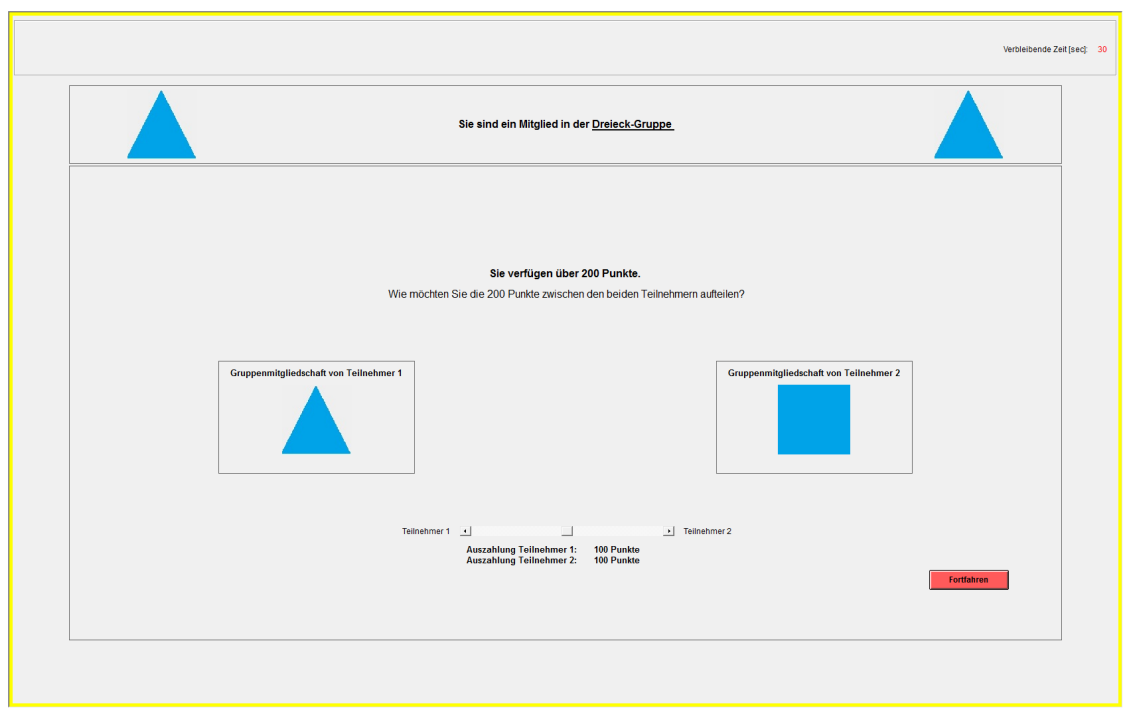




\section{References}

Akerlof, G. A., Kranton, R. E. (2000). Economics and identity. The Quarterly Journal of Economics, 115(3), 715-753.

Allcott, H., Braghieri, L., Eichmeyer, S., and Gentzkow, M. (2020). The welfare effects of social media. American Economic Review, 110(3), 629-76.

Aron, A., Aron, E. N., Smollan, D. (1992). Inclusion of Other in the Self Scale and the structure of interpersonal closeness. Journal of personality and social psychology, 63(4), 596.

Bénabou, R., and Tirole, J. (2011). Identity, morals, and taboos: Beliefs as assets. The Quarterly Journal of Economics, 126(2), 805-855.

Benjamin, D. J., Choi, J. J., Strickland, A. J. (2010). Social identity and preferences. American Economic Review, 100(4), 1913-28.

Bennet, S. (2015). January $2015-28$ of Time spent online is social networking. AdWeek.com. Accessed at http://www.adweek.com/socialtimes/time-spent-online/613474 on April $27,2020$.

Bennett, W. L., and Iyengar, S. (2008). A new era of minimal effects? The changing foundations of political communication. Journal of communication, 58(4), 707-731.

Bernard, M., Hett, F., Mechtel, M. (2016). Social identity and social free-riding. European Economic Review, 90, 4-17.

Bernhard, H., Fehr, E., and Fischbacher, U. (2006). Group affiliation and altruistic norm enforcement. American Economic Review, 96(2), 217-221.

Boen, F., Vanbeselaere, N., Feys, J. (2002a). Behavioral consequences of fluctuating group success: An Internet study of soccer-team fans. The Journal of social psychology, 142(6), 769-781.

Boen, F., Vanbeselaere, N., Pandelaere, M., Dewitte, S., Duriez, B., Snauwaert, B., ... Van Avermaet, E. (2002b). Politics and basking-in-reflected-glory: A field study in Flanders. Basic and Applied Social Psychology, 24(3), 205-214.

Brewer, M. B. (1999). The psychology of prejudice: Ingroup love and outgroup hate?. Journal of social issues, 55(3), 429-444.

Buser, T., and Dreber, A. (2016). The flipside of comparative payment schemes. Management Science, 62(9), 2626-2638. 
Charness, G., and Rabin, M. (2002). Understanding social preferences with simple tests. The Quarterly Journal of Economics, 117(3), 817-869.

Charness, G., Rigotti, L., and Rustichini, A. (2007). Individual behavior and group membership. American Economic Review, 97(4), 1340-1352.

Chen, R., Chen, Y. (2011). The potential of social identity for equilibrium selection. American Economic Review, 101(6), 2562-89.

Chen, R., Chen, Y., Liu, Y., Mei, Q. (2017). Does team competition increase pro-social lending? Evidence from online microfinance. Games and Economic Behavior, 101, 311-333.

Chen, Y., Li, S. X. (2009). Group identity and social preferences. The American Economic Review, 99(1), 431-457.

Chowdhury, S. M., Jeon, J. Y., and Ramalingam, A. (2016). Identity and group conflict. European Economic Review, 90, 107-121.

Cialdini, R. B., Borden, R. J., Thorne, A., Walker, M. R., Freeman, S., Sloan, L. R. (1976). Basking in reflected glory: Three (football) field studies. Journal of personality and social psychology, 34(3), 366 .

Currarini, S., Mengel, F. (2016). Identity, homophily and ingroup bias. European Economic Review, 90, 40-55.

Delgado, M. R., Schotter, A., Ozbay, E. Y., and Phelps, E. A. (2008). Understanding overbidding: using the neural circuitry of reward to design economic auctions. Science, $321(5897), 1849-1852$.

Eckel, C., Grossman, P. J. (2005). Managing diversity by creating team identity. Journal of Economic Behavior \& Organization, 58(3), 371-392.

Ellemers, N., Barreto, M. (2001). The impact of relative group status: Affective, perceptual and behavioral consequences. Blackwell handbook of social psychology: Intergroup processes, 325-343.

Ellemers, N., Spears, R., and Doosje, B. (1999). Social identity (p. 144). Blackwell: Oxford.

End, C. M., Dietz-Uhler, B., Harrick, E. A., Jacquemotte, L. (2002). Identifying with winners: A reexamination of sport fans' tendency to BIRG. Journal of Applied Social Psychology, 32(5), 1017-1030.

Facebook. 2016. April 2016. — Facebook Q1 2016 Results: Earnings Call Transcript. seekingalpha.com. Accessed at https://www.seekingalpha.com/article/ 
3968783-facebook-fb-mark-elliot-zuckerberg-q1-2016-results-earnings-call-transcript April 27, 2020.

Facebook. 2020. January 2020. — Facebook Reports Fourth Quarter and Full Year 2019 Results. Press Release. Accessed at https://www.investor.fb.com/investor-news/press-release-details/2020/ Facebook-Reports-Fourth-Quarter-and-Full-Year-2019-Results/default.aspx on April 27, 2020.

Festinger, L. (1954). A theory of social comparison processes. Human relations, 7(2), 117-140.

Fischbacher, U. (2007). z-Tree: Zurich toolbox for ready-made economic experiments. Experimental economics, 10(2), 171-178.

Gächter, S., Starmer, C., Tufano, F. (2015). Measuring the closeness of relationships: a comprehensive evaluation of the'inclusion of the other in the self'scale. PloS one, 10(6), e0129478.

Gentzkow, M. (2016). Polarization in 2016. Toulouse Network for Information Technology Whitepaper, 1-23.

Goette, L., Huffman, D., Meier, S. (2006). The impact of group membership on cooperation and norm enforcement: Evidence using random assignment to real social groups. American Economic Review, 96(2), 212-216.

Goette, L., Huffman, D., Meier, S., Sutter, M. (2012). Competition between organizational groups: Its impact on altruistic and antisocial motivations. Management science, 58(5), 948-960.

Henry, P. J., Butler, S. E., and Brandt, M. J. (2014). The influence of target group status on the perception of the offensiveness of group-based slurs. Journal of Experimental Social Psychology, 53, 185-192.

Herbst, L. (2016). Who pays to win again? The joy of winning in contest experiments. Working paper.

Hett, F., Kröll, M., and Mechtel, M. (2019). Choosing Who You Are: The Structure and Behavioral Effects of Revealed Identification Preferences. Working Paper.

Hewstone, M., Rubin, M., Willis, H. (2002). Intergroup bias. Annual review of psychology, 53(1), 575-604.

Homans, G. C. (1950). The Human Group. New Brunswck. 
Hornsey, M. J. (2008). Social identity theory and self-categorization theory: A historical review. Social and Personality Psychology Compass, 2(1), 204-222.

Kaakinen, M., Sirola, A., Savolainen, I., and Oksanen, A. (2020). Shared identity and shared information in social media: development and validation of the identity bubble reinforcement scale. Media Psychology, 23(1), 25-51.

Kidd, M., Nicholas, A., and Rai, B. (2013). Tournament outcomes and prosocial behaviour. Journal of Economic Psychology, 39, 387-401.

Klor, E. F., and Shayo, M. (2010). Social identity and preferences over redistribution. Journal of Public Economics, 94(3-4), 269-278.

Kosfeld, M., Neckermann, S. (2011). Getting more work for nothing? Symbolic awards and worker performance. American Economic Journal: Microeconomics, 3(3), 86-99.

Kranton, R., Pease, M., Sanders, S., Huettel, S. (2016). Groupy and non-groupy behavior: Deconstructing bias in social preferences. Mimeo.

Kuhnen, C. M., and Tymula, A. (2012). Feedback, self-esteem, and performance in organizations. Management Science, 58(1), 94-113.

Leach, C. W., Van Zomeren, M., Zebel, S., Vliek, M. L., Pennekamp, S. F., Doosje, B., ... Spears, R. (2008). Group-level self-definition and self-investment: a hierarchical (multicomponent) model of ingroup identification. Journal of personality and social psychology, 95(1), 144.

Mago, S. D., Samak, A. C., Sheremeta, R. M. (2016). Facing your opponents: Social identification and information feedback in contests.Journal of Conflict Resolution, 60(3), 459-481.

McLeish, K. N., Oxoby, R. J. (2011). Social interactions and the salience of social identity. Journal of Economic Psychology, 32(1), 172-178.

McPherson, M., Smith-Lovin, L., Cook, J. M. (2001). Birds of a feather: Homophily in social networks. Annual review of sociology, 27(1), 415-444.

Müller, D. (2019). The anatomy of distributional preferences with group identity. Journal of Economic Behavior \& Organization, 166, 785-807.

Mullen, B., Brown, R., Smith, C. (1992). Ingroup bias as a function of salience, relevance, and status: An integration. European Journal of Social Psychology, 22(2), 103-122.

Pariser, E. (2011). The filter bubble: What the Internet is hiding from you. Penguin UK. 
Pew Research Center. (2018). March 2018 - Social Media Use in 2018. pewresearch.org. Accessed at https://www.pewresearch.org/internet/2018/03/01/social-media-use-in-2018/ on April 27, 2020.

Pew Research Center. (2019). September 2019 - Millennials stand out for their technology use, but older generations also embrace digital life. pewresearch.org. Accessed at https:https: //www . pewresearch.org/fact-tank/2019/09/09/us-generations-technology-use/ on April 27, 2020.

Postmes, T., Haslam, S. A., Jans, L. (2013). A single-item measure of social identification: Reliability, validity, and utility. British journal of social psychology, 52(4), 597-617.

Robb, M. (2015). November 2015. — Tweens, teens, and screens: What our new research uncovers. Common sense media. Commonsensemedia.org. Accessed at https://www. commonsensemedia.org/blog/ tweens-teens-and-screens-what-our-new-research-uncovers on on April 27, 2020.

Roccas, S., Sagiv, L., Schwartz, S., Halevy, N., Eidelson, R. (2008). Toward a unifying model of identification with groups: Integrating theoretical perspectives. Personality and Social Psychology Review, 12(3), 280-306.

Rustagi, D., Veronesi, M. (2016). Social identity, attitudes towards cooperation, and social preferences: Evidence from Switzerland (No. 01/2016).

Sen, A. (2007). Identity and violence: The illusion of destiny. Penguin Books India.

Settle, J. E. (2018). Frenemies: How social media polarizes America. Cambridge University Press. Shayo, M. (2009). A model of social identity with an application to political economy: Nation, class, and redistribution. American Political science review, 103(02), 147-17.

Sheremeta, R. M. (2010). Experimental comparison of multi-stage and one-stage contests.Games and Economic Behavior,68(2), 731-747.

Slater, M. D. (2007). Reinforcing spirals: The mutual influence of media selectivity and media effects and their impact on individual behavior and social identity. Communication theory, 17(3), 281-303.

Sunstein, C. R. (2018). \# Republic: Divided democracy in the age of social media. Princeton University Press.

Sunstein, C. R. Republic. com 2.0 2007 Princeton University Press Princeton. New Jersey. 
Tajfel, H. (1972). Some developments in European social psychology. European Journal of Social Psychology, 2(3), 307-321.

Tajfel, H. (1974). Social identity and intergroup behaviour. Information (International Social Science Council), 13(2).

Tajfel, H. (1978). Differentiation between social groups: Studies in the social psychology of intergroup relations. Academic Press.

Tajfel, H. (1979). Individuals and groups in social psychology. British Journal of Clinical Psychology, 18(2), 183-190.

Tajfel, H., Billig, M. (1974). Familiarity and categorization in intergroup behavior. Journal of Experimental Social Psychology, 10(2), 159-170.

Tajfel, H., Turner, J. C. (1979). An integrative theory of intergroup conflict. The social psychology of intergroup relations, 33(47), 74.

Tajfel, H., Turner, J. C. (1986). The social identity theory of intergroup behaviour. In S. Worchel and W. G. Austin (Eds.), Psychology of intergroup relations 2nd ed., pp. 7-24, Chicago: Nelso.

Tropp, L. R., Wright, S. C. (2001). Ingroup identification as the inclusion of ingroup in the self. Personality and Social Psychology Bulletin, 27(5), 585-600.

Tucker, J. A., Theocharis, Y., Roberts, M. E., and Barberá, P. (2017). From liberation to turmoil: Social media and democracy. Journal of democracy, 28(4), 46-59.

Tucker, J. A., Guess, A., Barberá, P., Vaccari, C., Siegel, A., Sanovich, S., ... and Nyhan, B. (2018). Social media, political polarization, and political disinformation: A review of the scientific literature. Political polarization, and political disinformation: a review of the scientific literature (March 19, 2018).

Turner, J. C., Hogg, M. A., Oakes, P. J., Reicher, S. D., Wetherell, M. S. (1987). Rediscovering the social group: A self-categorization theory. Oxford: Blackwell.

Van Dick, R. (2001). Identification in organizational contexts: Linking theory and research from social and organizational psychology. International Journal of Management Reviews, 3(4), 265-283.

Van Dick, R. V. (2004). My job is my castle: Identification in organizational contexts. International Review of Industrial and Organizational Psychology 2004, Volume 19, 171-203. 
Vidal, J., Nossol, M. (2011). Tournaments without prizes: Evidence from personnel records. Management science, 57(10), 1721-1736.

Wagner, U., Zick, A. (1990). Psychologie der Intergruppenbeziehungen: Der 'Social Identity Apporach'. Gruppendynamik, 21.

Wallace, K. (2015). November 2015 — Teens spend a 'mind-boggling' 9 hours a day using media, report says. CNN.com. Accessed at https:

//edition.cnn.com/2015/11/03/health/teens-tweens-media-screen-use-report/ on April 27, 2020.

Wann, D. L., Hamlet, M. A., Wilson, T. M., Hodges, J. A. (1995). Basking in reflected glory, cutting off reflected failure, and cutting off future failure: The importance of group identification. Social Behavior and Personality: an international journal, 23(4), 377-388.

Weisel, O. (2016). Social motives in intergroup conflict: Group identity and perceived target of threat. European Economic Review, 90, 122-133. 


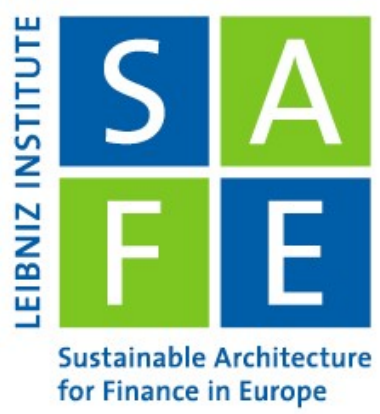

\section{Recent Issues}

No. 280 Konstantin Bräuer, Andreas Hackethal, Tobin Hanspal

No. 279 Tobin Hanspal, Annika Weber, Johannes Wohlfart

No. 278 Sandra Eckert

No. 277 Dominique M. Lammer, Tobin Hanspal, Andreas Hackethal

No. 276 Massimiliano Caporin, Loriana Pelizzon, Alberto Plazzi

No. 275 Loriana Pelizzon, Max Riedel, Zorka Simon, Marti Subrahmanyam

No. 274 Christopher Busch, Alexander Ludwig

No. 273 Di Bu, Tobin Hanspal, Yin Liao, Yong Liu

No. 272 Christine Laudenbach, Benjamin Loos, Jenny Pirschel, Johannes Wohlfart

No. 271 Pietro Dindo, Andrea Modena, Loriana Pelizzon

No. 270 Mario Bellia, Kim Christensen, Aleksey Kolokolov, Loriana Pelizzon, Roberto Renó

No. 269 Ester Faia, Maximilian Mayer, Vincenzo Pezone

No. 268 Lorenzo Maria Levati, Marie Lalanne

No. 267 Wataru Kureishi, Hannah PaulePaludkiewicz, Hitoshi Tsujiyama, Midori Wakabayashi
Consuming Dividends

Exposure to the COVID-19 Stock Market Crash and its Effect on Household Expectations

EU Agencies in Banking and Energy Between Institutional and Policy Centralisation

Who Are the Bitcoin Investors? Evidence from Indirect Cryptocurrency Investments

Does Monetary Policy Impact International Market Co-Movements?

Collateral Eligibility of Corporate Debt in the Eurosystem

Higher-Order Income Risk Over the Business Cycle

Financial Literacy and Self-Control in FinTech: Evidence from a Field Experiment on Online Consumer Borrowing

The Trading Response of Individual Investors to Local Bankruptcies

Risk Pooling, Leverage, and the Business Cycle

High-Frequency Trading During Flash Crashes: Walk of Fame or Hall of Shame?

The Value of Firm Networks: A Natural Experiment on Board Connections

The Impact of Job Referrals on Employment Outcomes in Top Corporate Positions

Time Preferences over the Life Cycle 